\title{
New system for measuring impact vibration on floor decking sheets
}

\section{Carlos Moron ${ }^{1}$,*, Alfonso Garcia ${ }^{1}$ and Daniel Ferrandez ${ }^{1}$}

1 Sensors and Actuators Group, Department of Tecnología de la Edificación, Universidad Politécnica de Madrid, 28040 Madrid, Spain; E-Mails: carlos.moron@upm.es; alfonso.garciag@upm.es; daniel.ferrandez.vega@alumnos.upm.es

* Author to whom correspondence should be addressed; E-Mail: carlos.moron@upm.es; Tel.: +34-91-336-7583; Fax: +34-91-336-7637.

Published: 1 June 2014

\begin{abstract}
Currently there is a narrow range of materials that are used as attenuators of impact noise and building vibrations. Materials used in construction such as elastic materials, must meet the requirement of having very low elasticity modulus values. For the determination of the material elasticity modulus used and the acoustic insulation of the same, a costly and difficult to execute testing is required. The present paper exposes an alternative system more simple and economic, consisting of a predefined beating device and a sensor able to determine, once produced the hit, the energy absorbed by the plate. After the impact being produced, the plate undergoes a deformation which absorbs part of the energy, being the reminding one transmitted to the slab and, at the same time, causing induced airborne noise in the adjoining room. The plate absorbed its power through its own deformation, which is measured with the help of the capacitive sensor. Properly defining the geometry of the plates, after the execution of the test, a relationship between the values proposed in this research and the acoustic behavior demanded by the Spanish will be tried to be establish.
\end{abstract}

Keywords: vibration; impact; capacitive sensor; elasticity modulus

\section{Introduction}

In the building field it is of special interest know the behavior of different materials against impact noise attenuation. As for example, certain elastic coatings or certain constructive solutions, such as 
floating slabs, enable reducing vibration transmissions and provide better soundproofing against this kind of noise [1]. Thus, one of the main parameters of the resistance of materials and especially among construction materials is the elasticity modulus, which is obtained from the relation existing between the stress to which a body is subjected and the deformation experienced by this.

The usual methods performed in the laboratory for the determination of the elastic modulus, are based on static test that measure with precision the stresses and deformations produced on the material. There are a large number of studies that to the addition of materials in concrete and its improvement over the impact noise transmission [2,3]. Also, articles about how to determine the Young modules in this material, based on application of acoustic waves generated from impacts can be found [4] and [5], as well as sensors, able to determine the position of these impacts on metal parts [6].

However, in the field of prefabricated tiles, studies enabling to determine the coefficient of acoustic reduction, from the beating of a plate with a given load, and depending on the energy absorbed from their deformation, beyond tests with accelerometers proposed by the standard UNE EN 140-3, are few. Dropping a known load from a known height, we can determine the energy introduced to the system. It is easy to measure the capacity of the sensor before the impact, and also to determine the capacity of the system during the impact. Thus with this difference between capacities, obtained as a result of the variation of the gap between the plates of the sensor, the deformation suffered by the plate and the energy that it has absorbed to get deform can be determined.

The main objective of this article is to show the development of a system that allows an alternative test faster and more economical to the one proposed by the current standard UNE EN 140-7, which provides reliable results and that can be used as a reference tool before the standardized tests.

\section{Experimental Process}

\subsection{Determination of the plate's shape}

One of the main ideas of this paper was to determine in an analytical way, the most appropriate shape for the plates footing, and subsequently to test its suitability for the trial execution.

Figure 1. (a) Automatic mixer. (b) Fill and leveled of samples. (c) Standard simple tested.

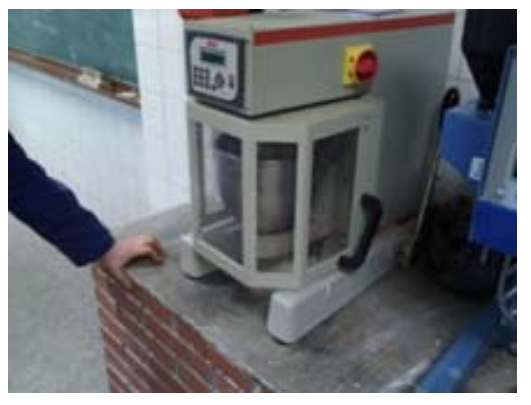

(a)

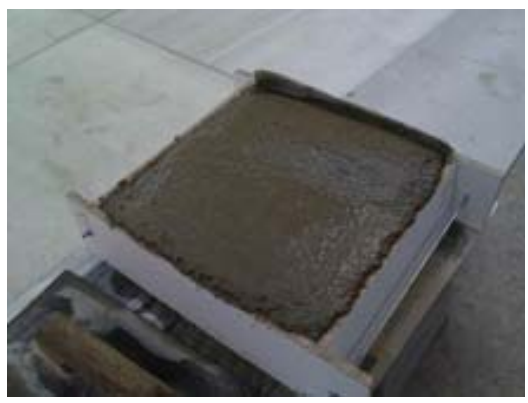

(b)

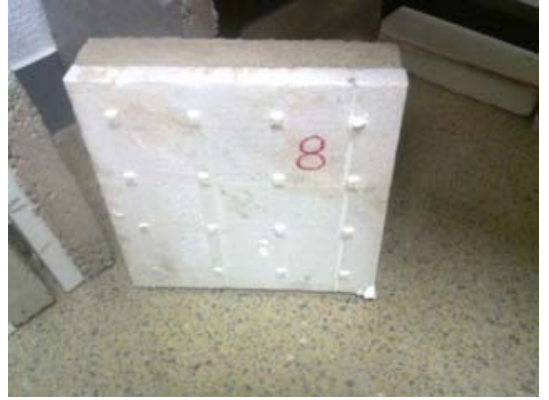

(c)

The tiles used, are mixed because they are formed by a lower base of EPS (expanded polystyrene) and a top layer of mortar (Figure 1(a)). Following, thicknesses and the manufacturing process of each of the components are detailed. Each of them has the dimensions of $500 \times 500 \mathrm{~mm}^{2}$ (Figure 1(b)). Since the industrialized production of underfloor heating system is done by a molding process, and this 
requires several months for its implementation, in this paper, it was chosen to product plates from numerical control.

EPS plate design was treated using a drawing program assisted by computer and a numerical control application. This way base blocks were made of truncated cone shape to avoid possible damage by cutting at the junction of the base (Figure 1(c)).

Plates in total have a thickness similar to those used in construction of approximately $40 \mathrm{~mm}$. For the realization of the slab mortar, a dosing by weight of 1 - 3 - 0.5 (cement - sand - water) has been used, homogenizing the mix with the help of an automatic mixer. Since when these mortars are made on worksite, the only conditions taken into account are the flatness and moisture content; terms of plasticity have not been set for this tests.

The mold used as formwork was wooden, and the dumping and compacted of the pieces was done manually, due to the small size of each of the samples, smoothing the surface with the trowel. Subsequently, pieces in their own mold were introduced in the humid Chamber, removing them from the mold 24 hours later and keeping the plates in this Chamber for another 7 days. The rest of curing was held outdoors, on the laboratory shelves, all of them were located in the same area, with the idea of avoiding differences due to heat or power in the curing process.

\subsection{Beating hammer design}

Figure 2. Hammer placed and levelled on o wood blocks.

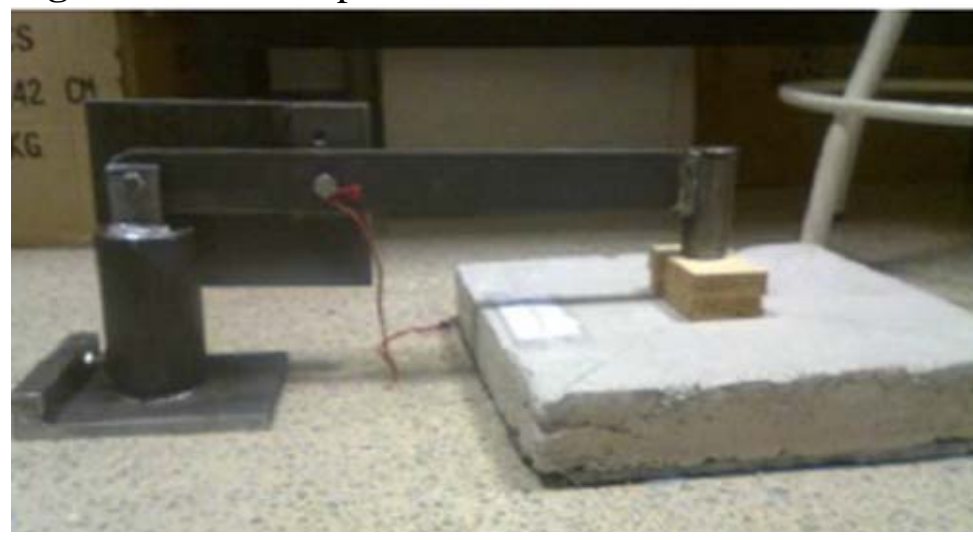

The fundamental premise followed to design the beating hammer, were that all impacts occurred in the most regular a uniform way, fulfilling so with the pendulum.

This way, if the hammer shaft is on an axis, the beating will always follow the same path (Figure 2). Then, we will set the starting point at the desired height with the help of a bolt that goes

through the axis of the hammer. Thus, the fall will always be under the same conditions simply by removing the bolt that holds it. Finally, the leveling of the impact point on the tiles will be performed with the help of a few wooden chocks.

The hammer head has a round shape with a $15 \mathrm{~mm}$ radius and a sphericity exceeding $500 \mathrm{~mm}$, so that it is in accordance with the standard UNE EN ISO 140 - 3.

\subsection{Sensor test design}

The sensor should be able to determine, once the impact is produced, the power adsorbed by the plate. Known the hammer mass and the height of the drop, the potential energy available is known. Once the impact is produced, the plate undergoes a deformation absorbing part of that power, and transmitting the remaining to the adjacent area as impact noise. The energy which adsorbs the plate makes it through its own deformation. Thus, the sensor should be able to determine deformation that 
occurs on the test plate. To do this, the chosen device was a variable reactance sensor, capable of measuring the difference that occurs in the capacity of a condenser.

The sensor is based on the variation of capacity of two copper plates placed at the bottom of the sample. Between the two copper plates is placed another material which creates a space between them. When the beatings happen, the sample deforms, by compressing itself and pushing the copper plates against each to the other, thus varying so the geometry of the condenser, and therefore their capacity. In our case, this variation is detected by measuring the oscillation frequency of a self-oscillator circuit. So, the mechanical oscillation modulates the output frequency of the self-oscillator circuit. Making a frequency demodulation on obtain the mechanical vibration of plate.

\section{Methodology}

Previous to the test it is necessary to level the plate and adjusts the beating hammer, by setting the hammer in a lower position (level at $0^{\circ}$ when the hammer head will be placed in contact with the top plate of the sample).

Once the hammer is raced till the fixed position of beating, the test begins by dropping the hammer that impacts over the plate. Upon the impact, the plates of the sensor set under the tile vary their relative position, varying so the capacity of the condenser which they form due to plate deformation

Figure 3. Graphics before (blue) and after (red) the impact.

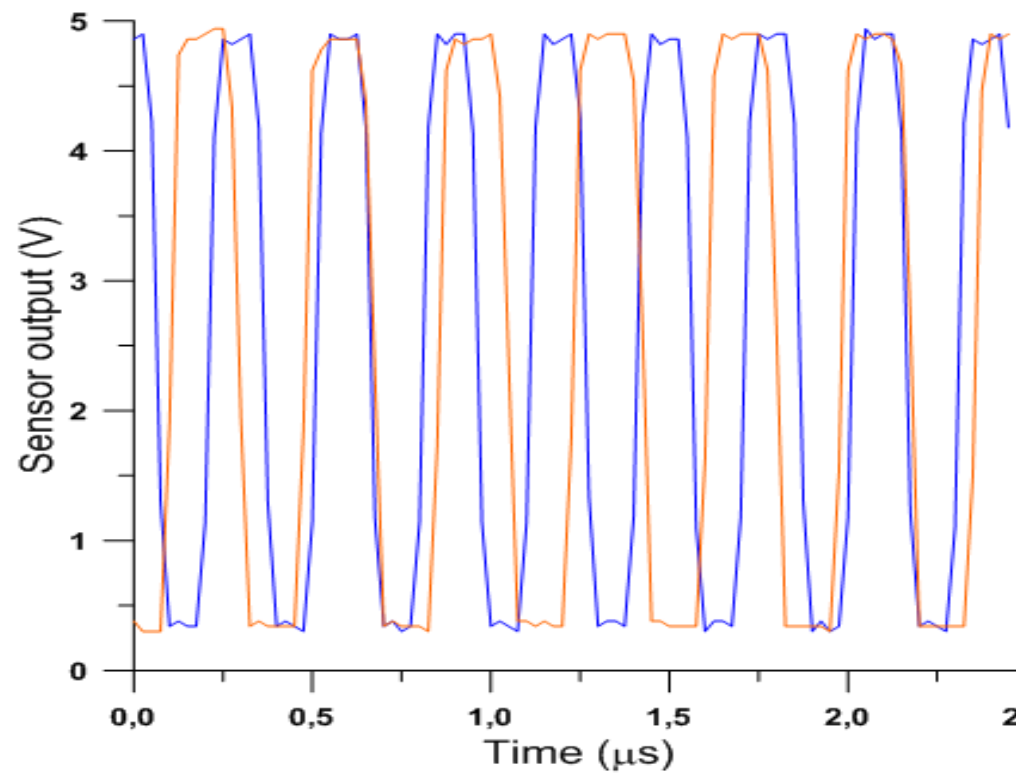
and vibration. The sensor detects this vibration that is traduced as a frequency modulation over the fundamental frequency of autooscillating sensor circuit. By demodulating this signal with the adequate electronic circuit, on obtain the vibration induced in the plate as result of the hammer impact. Gradually the deformation will be cushioning until reaching its starting point.

In figure 3, it is shown the output of sensor before the hammer impacts over the plate (blue trace) and at the moment immediate subsequent to the impact (red). It can be see that the frequency output decreases when sensor detects a deformation due to the impact.

The final results obtained, after frequency demodulation of sensor output, are shown in figure 4 . The greater the deformation of plates is, more energy will be absorbed, and therefore less energy transmitted as of impact noise, and better insulation it will be. The biggest jump in frequency will be the deformation indicator and therefore of the absorbed power. 
Figure 4. Response curves with different pieces of EPS.

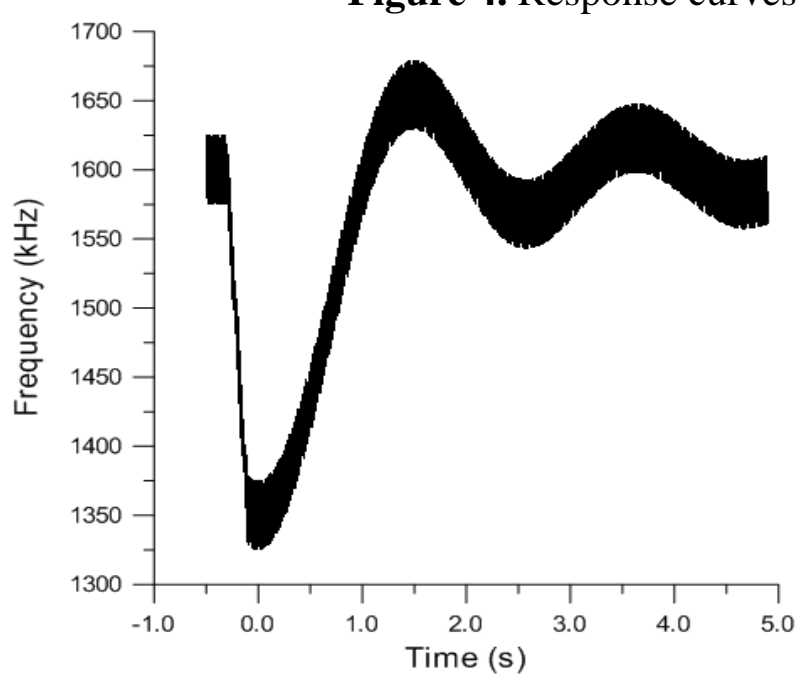

(a)

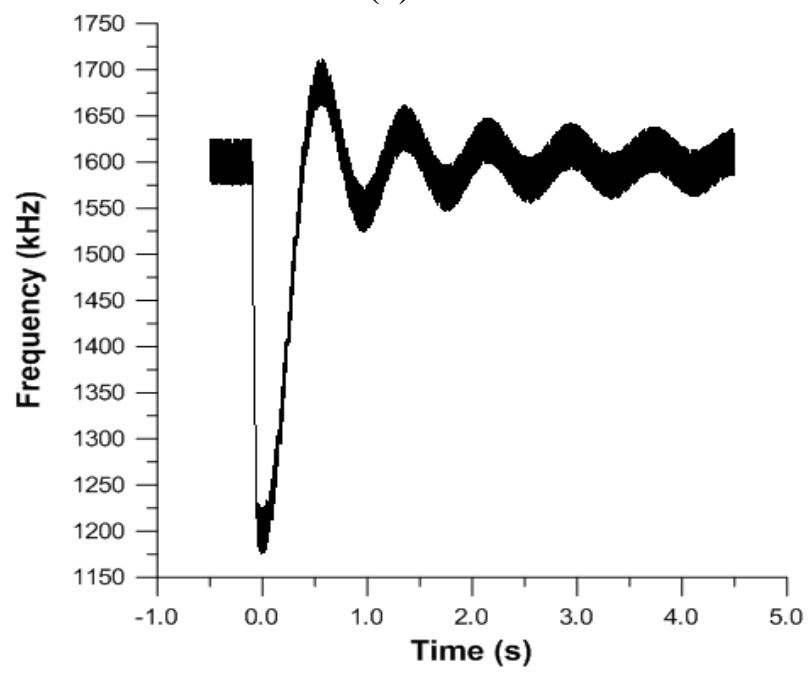

(c)

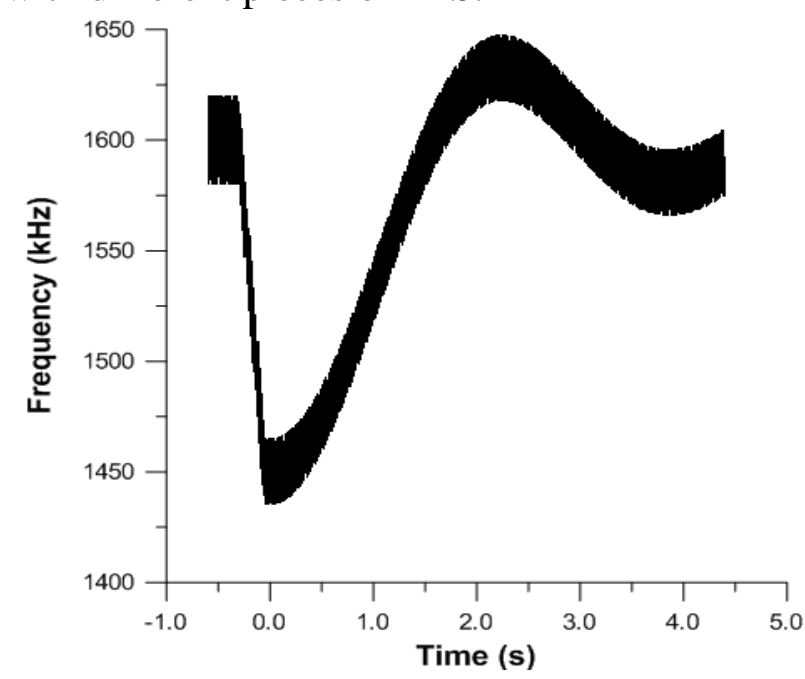

(b)

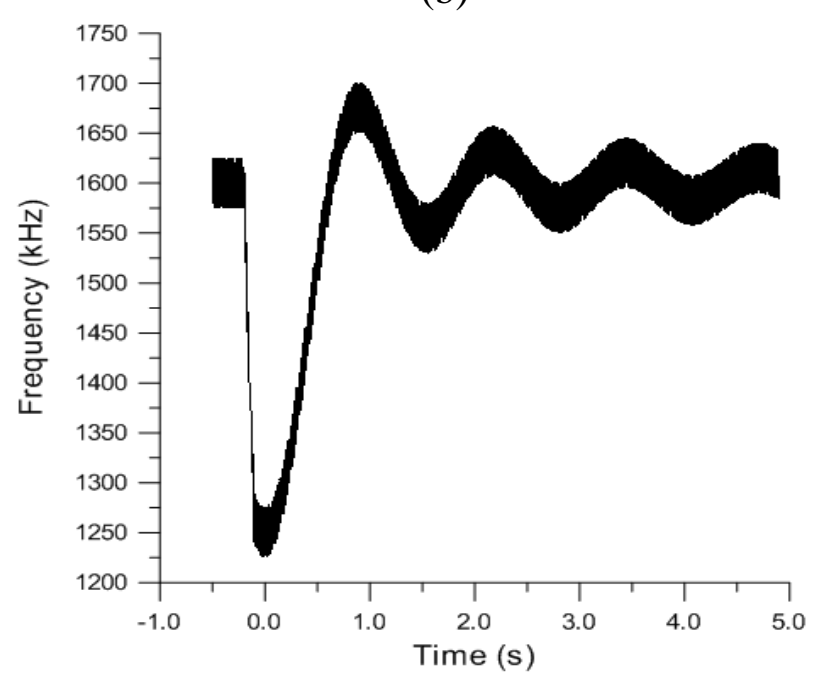

(d)

\section{Results and Discussion}

The measures, as already mentioned, were carried out and each measure covered 5 seconds, which is bought about 8 million of periods of the signal at frequency sensor base. This ensures, on the one hand enough time of acquisition to pick up the response of the material and on the other hand guarantees that the number of samples per period is enough to determine with precision the variations in frequency.

From these measurements it is obtained the frequency response as a function of time, so to say, the material response to the received bump. Below are four response curves (Figure 4) with different pieces of EPS corresponding to four plates, in which all of them, the zero has been set at the time of the impact.

These graphs show that the methodology tested is able to get answers from the different analyzed samples, and the answers obtained show different temporal behaviors (and therefore different spectral responses) that could be correlated with their acoustic behavior. 
In addition, as can be seen in the graphics of Figure 4, the obtained frequencies are affected by a considerable noise. This is due to the method of obtaining thereof. This can be solved by improving an electronic demodulator that would enable to capture the signals with less noise and better resolution.

\section{Conclusions}

From data obtained and the significant graphics represented, it can be clearly seen the moment in which the impact has been produced on each of the plates. Furthermore, after this impact, there is a temporary response and therefore the spectrum thereof could be obtained.

On the other hand, the response of the plate is clearly distinguishable in the test, as a constant frequency behavior is observed since the beginning of the same until the moment of impact, in which a very pronounced a drop and rise takes place, after which it is passed to a gradually recovery until they reach a frequency equal to the initial one.

All of this leads to think of the possible applications of this sensor, as a method of stopping impacts on slabs, which can range from text aimed at acoustic normalization of prefabricated tiles, to integration of itself in more complex structures as an alarm system.

\section{References and Notes}

1. Arau, H. In Nueva Arquitectura. El ruido de impacto en forjado in Artículos técnicos sobre acústica, ISSN 1135 - 3384, 1996; pp. 37-52.

2. Tutikian, B.F.; Nunes, M.F; Leal, L.C.; Marquetto, L. Hormigón ligero con agregado reciclado de EVA para atenuación del ruido de impacto. Materiales de Construcción, 2013, 63, pp. 309-316.

3. Morais, L.; Pereira, A.; Godinho, L. Experimental characterization of the impact noise insulation of floating slab systems and floating floor system using a small footprint. Proceeding of the VI Congreso Latinoamericano de Confort en Ambiente Construido, ANTAC, 2009, in CD-ROM.

4. Rosell, J.R.; Cantalapiedra, I.R. Método simple para la determinación del módulo de Young dinámico a partir de una excitación por impacto aplicada a morteros de cal y cement. Materiales de Construcción, 2011, 61, pp. 39-48.

5. Nagy, A. Determination of E-modulus of young concrete with nondestructive method. J. Mater. Civ. Eng., 1997, 9(1), pp. 15-20.

6. Somolinos, J.R; Morales, R.; García, A.; Morón, C. Piezoelectric sensors system for impact detecting. Sensor Letters, 2013, 11, pp. 128-130.

(C) 2014 by the authors; licensee MDPI, Basel, Switzerland. This article is an open access article distributed under the terms and conditions of the Creative Commons Attribution license (http://creativecommons.org/licenses/by/3.0/). 